\title{
Regional Risk Assessment Methodology Considering the Vulnerability of Chemical Industrial Park
}

\author{
D.M. DONG \& B.R. WANG \\ School of Business, East China University of Science and Technology, Shanghai, China
}

\begin{abstract}
With the rapid development of urbanization and industrialization, chemical industrial parks were spring up all over the country. The research demands on the regional risk assessment method are pressing due to the high demands caused by the rapid development of chemical industrial park in China. The significant impacts of vulnerability of chemical industrial park on the regional risk assessment are not considered in the current practices due to the lack of in-depth understanding of the internal mechanism. In order to consider the impacts of vulnerability on the regional risk assessment of chemical industrial park, the regional risk was divided into two parts: inherent risk and risk caused by vulnerability. This method proposed in this paper can effectively consider the impact of vulnerability on the regional risk assessment of chemical industrial park.
\end{abstract}

KEYWORD: Chemical industrial park, Vulnerability, Regional risk assessment, Accumulative principle

\section{INTRODUCTION}

Now China is undergoing a rapid period of urbanization and industrialization. Over the past 30 years, the urban share of the Chinese population has risen from $20 \%$ to $46 \%$ (Wang, B.T. 2008). In cities such as Beijing, Shanghai and others on the coast, if they are planning improperly, once accident occurs, heavy economic loss and severe casualty would result (Shi, L.C. 2009).

CHEN Guohua (Chen, G.H. 2006) found that vulnerability has a significant impact on the regional risk assessment of chemical industrial park. It shows that calculated result considering vulnerability of chemical industrial park is more accurate than those without considering. Shi peijun (Shi, P.J. 2002) found that in the vulnerability of chemical industrial park is one of the most important factors causing disaster. The intensity of hazard-formative factors and the vulnerability of hazard-affected bodies decide the extent of disaster effects (Shi, P.J. 2009). After the review of the previous relevant literature (Chen, G.H. 2006), we could find that the scholars got good agreements between the result considering vulnerability of chemical industrial park and the practical risk distribution. Therefore, determination of vulnerability index and regional risk assessment methodology considering the vulnerability are of vital meaning to the healthy and rapid development of chemical industrial park.

\section{CONCEPT AND CONNOTATION OF VULNERABILITY}

For the sake of different applications, various definitions of vulnerability have been proposed by different researchers. Vulnerability (Zhang B. 2009) is a state of mind. Vulnerability is the response of hazard-affected bodies to accidents exposure and sensibility. So vulnerability is the vulnerable to damage and loss nature of hazard-affected bodies. It is the inherent nature of chemical industrial park. The vulnerability of chemical industrial park will be significantly amplified due to the external disturbance (Sun A.J. 2011). Vulnerability to be inherent attribute of chemical industrial park.

\section{RISK COMPENSATION INDEX ANALYSIS CONSIDERING VULNERABILITY}

In order to considering the vulnerability impacts of chemical industrial park on the regional risk assessment, the vulnerability of human, equipment and environment were analyzed in this paper. The risk compensation coefficient considering vulnerability was present according to analysis result in the end. 


\subsection{Risk compensation coefficient considering human's vulnerability}

Vulnerability of human is the one kind of facts (McIntyre A. 2003). Vulnerability of human will become much obvious when people face major hazard accidents. International experiences indicated that the more population density, the closer distance of major hazard accidents, vulnerability is higher. Vulnerability of human is different with age structure, health condition, training degree and information receiving capacity.

\subsection{Risk compensation coefficient considering equipment's vulnerability}

Fire facilities and medical facilities will usually be given much consideration in the design and operation of factories. If the rescue measures are designed reasonable, the harms of accidents will be much decreased (McIntyre A. 2003). Risk compensation coefficient considering fire facilities and medical facilities vulnerability is of practical importance to accurately reflect the risk of chemical industrial park.

\subsubsection{Fire rescue compensation}

In our country, it averagely takes more than 5 minutes for a fire engine to arrive on the scene after the accident is happened. So the response time is $40 \mathrm{~s}$ in this paper. the rescue effort of fire engine is almost useless to the victims of major hazard accidents. The fixed fire facilities of factories can detect and call the police when the fire started, So it plays an important role in avoid of human injury and relief of property.

Response time refers to the time it takes for the automatic spraying system to respond to the signal sent by fire alarm device. Due to the strong thermal radiation in dead zone, the fixed fire device has a weaker rescue effect on the victims. However, it has an obvious recue effect on the victims in the slight wound zone for its weaker thermal radiation (Tang Q.X. 2010). So the fire rescue compensation coefficient should be different in different zone. Those fire rescue compensation coefficients are shown in Table 1.

Table 1. The influence of fire rescue facilities on the accident

\begin{tabular}{|c|c|c|c|}
\hline \multicolumn{3}{|c|}{ Risk compensation index } & \multirow{2}{*}{$\begin{array}{c}\text { Compensation } \\
\text { coefficient }\end{array}$} \\
\hline $\begin{array}{c}\text { Fire } \\
\text { facilities }\end{array}$ & $\begin{array}{c}\text { Respond } \\
\text { time }\end{array}$ & Zone & \\
\hline \multirow{3}{*}{$\begin{array}{l}\text { Fixed fire } \\
\text { facilities }\end{array}$} & \multirow{3}{*}{$t \leq 10 s$} & Dead zone & 0.90 \\
\hline & & Seriously injured zone & 0.85 \\
\hline & & Slight wound zone & 0.80 \\
\hline \multirow{3}{*}{$\begin{array}{l}\text { Fixed fire } \\
\text { facilities }\end{array}$} & \multirow{3}{*}{$t \leq 40 s$} & Dead zone & 0.95 \\
\hline & & Seriously injured zone & 0.90 \\
\hline & & Slight wound zone & 0.85 \\
\hline
\end{tabular}

\subsubsection{Medical rescue compensation}

The compensation zone considering medical rescue was divided into 5-min-zone and 10-min-zone according to the time took for medical staff to arrive the scene (Chen, G.H. 2006).

Due to different damage zone has different sensitivity to the different recue time and each damage zone has its own medical rescue compensation coefficient (Tang Q.X. 2010). Victims of slight wound zone usually injured light, so victims have a lower sensitivity to the rescue time. Victims of dead zone have a higher sensitivity to the rescue time for its great damage. The shorter rescue time, the better rescue effect has. Those fire rescue compensation coefficients are shown in Table 2.

Table 2. The influence of medical rescue facilities on the accident

\begin{tabular}{|c|c|c|}
\hline \multicolumn{2}{|c|}{ Risk compensation index } & \multirow{2}{*}{$\begin{array}{c}\text { Compensation } \\
\text { coefficient }\end{array}$} \\
\hline Rescue time & Zone & \\
\hline \multirow{3}{*}{$t_{f} \leq 5 \mathrm{~min}$} & Dead zone & 0.80 \\
\hline & Seriously injured zone & 0.85 \\
\hline & Slight wound zone & 0.90 \\
\hline \multirow{3}{*}{$t_{f} \leq 10 \mathrm{~min}$} & Dead zone & 0.85 \\
\hline & Seriously injured zone & 0.90 \\
\hline & Slight wound zone & 0.95 \\
\hline
\end{tabular}

\subsection{Risk compensation coefficient considering environmental vulnerability}

If leak accidents once occur in chemical plants, a great lot of noxious chemical will be discharged to the environment, and it causes serious environmental pollution. Compared with other pollutants, leak accidents will cause serious environmental pollution and ecological damage as it can be existed for a long time in environment.

\subsection{Regional risk assessment method considering the vulnerability}

Three commonly used approaches for Land-Use Planning vicinity of chemical sites were reviewed briefly: generic distances, consequence-based approach, and risk-based approach (Wang H.D. 2012).

The significant impacts of vulnerability of chemical industrial park on the regional risk assessment are not considered in the current practices due to the lack of in-depth understanding of the internal mechanism. In order to consider the impacts of vulnerability on the regional risk assessment of chemical industrial park, the regional risk was divided into two parts: inherent risk and risk caused by vulnerability. This method proposed in this paper can effectively consider the impact of vulnerability on the regional risk assessment of chemical industrial park. The research framework of this paper is shown as Figure 1. 


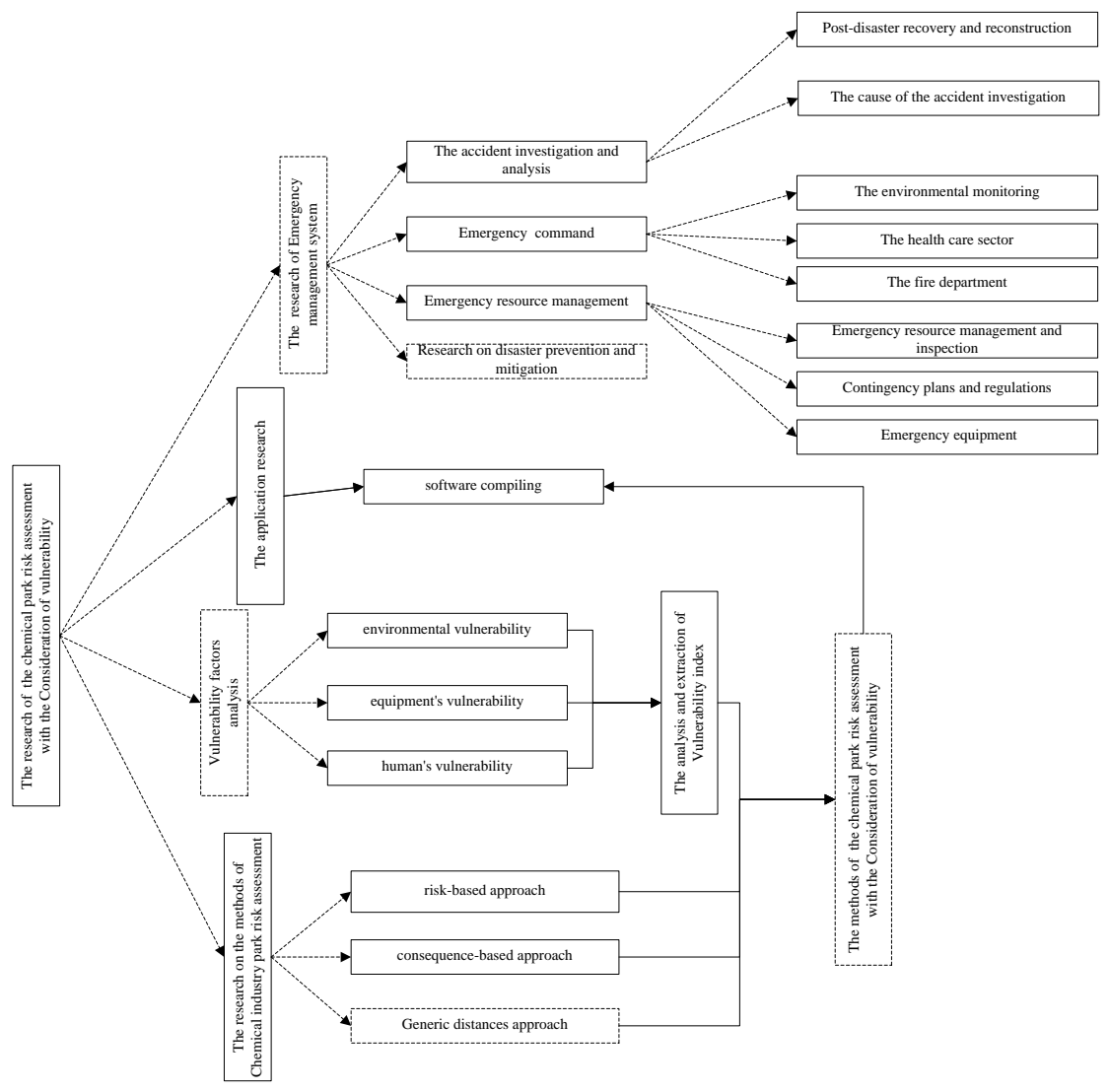

Figure 1. The research framework of this paper

\section{THE PROJECT CASE}

\subsection{Basic profile}

Shanghai Songjiang Industrial Zone, founded in July 1992, is the first municipal-level industrial zone. Songjiang industrial zone covers an area of about 43.69 square kilometers, including one phrase of the industrial district, the east new district and the western science park. The distribution for Songjiang industrial zone major hazards are shown in Table.3.

\subsection{Inherent risk of Songjiang industrial zone}

In order to accurately and effectively assess the industrial risk of the vulnerability considerations, the risk assessment software of chemical industrial park considering vulnerability was developed by the author. The probability of occurrence, consequence model, individual risk contour and social risk F-N curve of chemical industrial park can be obtained conveniently according to the software developed. The software interface is shown in Figure 2.

Table 3. The distribution of Songjiang industrial zone major hazard

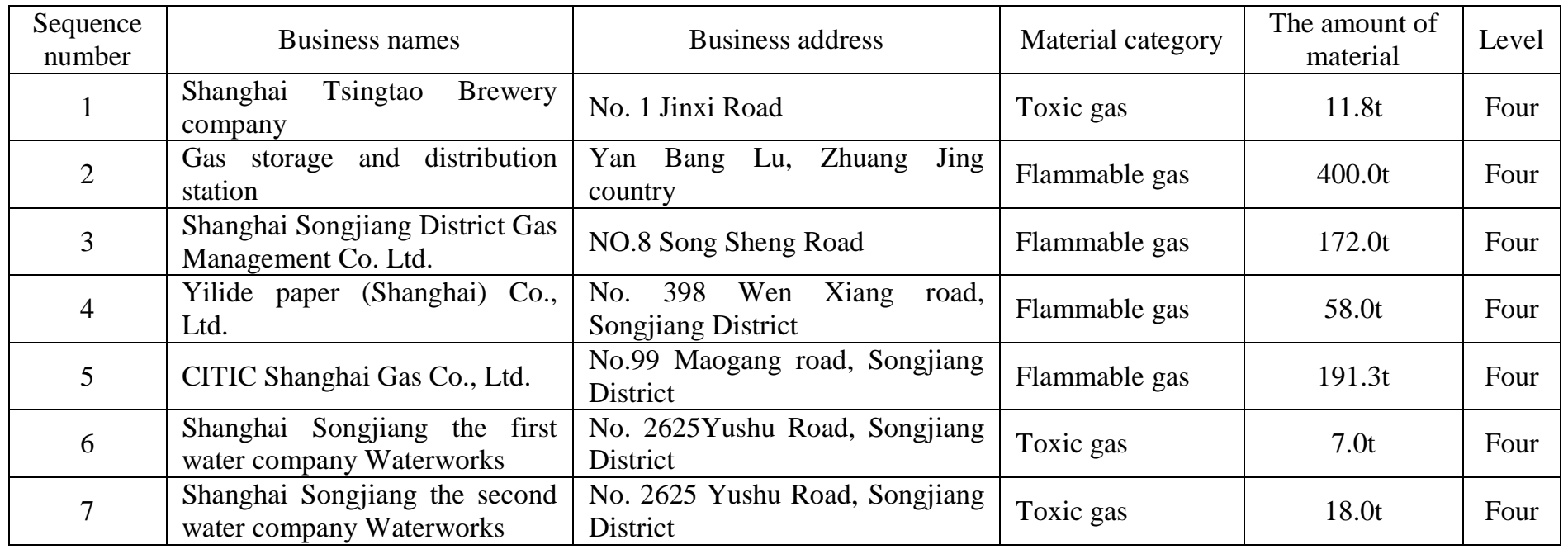




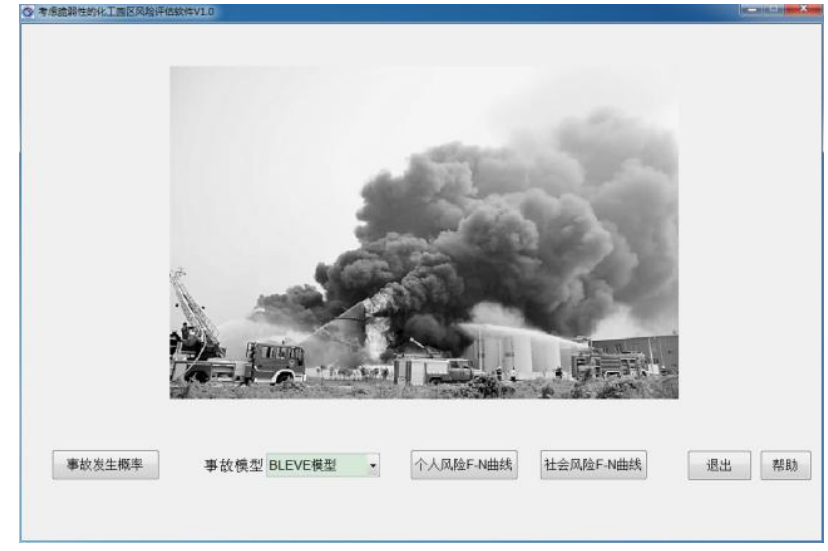

Figure 2. The risk assessment software of chemical industrial park considering vulnerability

The fire accident probability is 0.1556 according to the result. Then the fire explosion accident probability of Songjiang industrial zone can be obtained by the following equations.

$f=0.1556 \times \frac{37}{5490}=1.049 \times 10^{-3}$

The dead radius, seriously injured radius and slight wound radius can be obtained according to the proposed method, as shown Table 4.

Table 4. Accident consequences severity

\begin{tabular}{|c|c|c|c|c|c|}
\hline \multirow{2}{*}{2} & $\begin{array}{c}\text { Consequences } \\
\text { model }\end{array}$ & $\begin{array}{c}\text { dead } \\
\text { radius }\end{array}$ & $\begin{array}{c}\text { seriously } \\
\text { injured } \\
\text { radius }\end{array}$ & $\begin{array}{c}\text { slight } \\
\text { wound } \\
\text { radius }\end{array}$ & Choice \\
\cline { 2 - 6 } & BLEVE & $428.2 \mathrm{~m}$ & $540.0 \mathrm{~m}$ & $828.8 \mathrm{~m}$ & $\sqrt{ }$ \\
\hline \multirow{2}{*}{3} & VCE & $28.0 \mathrm{~m}$ & $73.9 \mathrm{~m}$ & $132.8 \mathrm{~m}$ & \\
\cline { 2 - 6 } & BLEVE & $399.3 \mathrm{~m}$ & $504.3 \mathrm{~m}$ & $775.2 \mathrm{~m}$ & $\sqrt{ }$ \\
\hline \multirow{2}{*}{4} & BLEVE & $26.5 \mathrm{~m}$ & $70.3 \mathrm{~m}$ & $126.3 \mathrm{~m}$ & \\
\cline { 2 - 6 } & VCE & $170.0 \mathrm{~m}$ & $307.1 \mathrm{~m}$ & $477.8 \mathrm{~m}$ & $\sqrt{ }$ \\
\hline \multirow{2}{*}{5} & $419.4 \mathrm{~m}$ & $529.1 \mathrm{~m}$ & $812.5 \mathrm{~m}$ & $87.9 \mathrm{~m}$ & \\
\cline { 2 - 6 } & $27.5 \mathrm{~m}$ & $72.8 \mathrm{~m}$ & $130.9 \mathrm{~m}$ & $27.5 \mathrm{~m}$ & $\sqrt{ }$ \\
\hline
\end{tabular}

The toxic gases mainly include chlorine and ammonia in this case. Gauss fume mode was used to calculate the gas leakage. The chlorine leaking was discussed as an example.

\subsection{Risk compensation coefficient considering equipment's vulnerability}

In order to consider the impact of vulnerability on the risk assessment of chemical industrial park, the personal vulnerability, equipment vulnerability and environmental vulnerability were calculated in the case analysis.

\subsubsection{Personal vulnerability}

Due to victims of different damage zone have different sensitivity to the personal vulnerability and each damage zone has its own compensation coefficient. The risk compensation coefficient considering personal vulnerability is shown in Table5.

Table 5. The risk compensation coefficient considering personal vulnerability

\begin{tabular}{|c|c|}
\hline Zone & Compensation coefficient \\
\hline Dead zone & 1.20 \\
\hline Seriously injured zone & 1.15 \\
\hline Slight wound zone & 1.10 \\
\hline
\end{tabular}

\subsubsection{Equipment's vulnerability}

The risk compensation coefficient considering equipment's vulnerability is shown in Table 1 and Table 2. The respond time of fire facilities and rescue time of medical facilities are 40 seconds and 5 minutes

\subsubsection{Environmental vulnerability}

The risk compensation coefficient considering environmental vulnerability is shown Table 6.

Table 6 . The risk compensation coefficient considering environmental vulnerability

\begin{tabular}{|c|c|}
\hline Zone & Compensation coefficient \\
\hline Dead zone & 1.15 \\
\hline Seriously injured zone & 1.10 \\
\hline Slight wound zone & 1.05 \\
\hline
\end{tabular}

\subsubsection{The coefficient of risk compensation}

The final compensation coefficient considering vulnerability can be attained by the following equations on the basis of previous result.

The risk compensation coefficient of dead zone:

$$
\begin{aligned}
C_{1} & =C_{p 1} \times C_{m 1} \times C_{e 1}=1.20 \times 0.80 \times 0.95 \times 1.15 \\
& =1.11435
\end{aligned}
$$

The risk compensation coefficient of seriously injured zone:

$$
\begin{aligned}
C_{2} & =C_{p 2} \times C_{m 2} \times C_{e 2}=1.15 \times 0.85 \times 0.90 \times 1.10 \\
& =0.967725
\end{aligned}
$$

The risk compensation coefficient of Slight wound zone:

$$
\begin{aligned}
C_{3} & =C_{p 3} \times C_{m 3} \times C_{e 3}=1.10 \times 0.90 \times 0.85 \times 1.05 \\
& =0.883575
\end{aligned}
$$

According to the above calculation, we can get the final compensation coefficient of vulnerability as figure 3 shown below: 


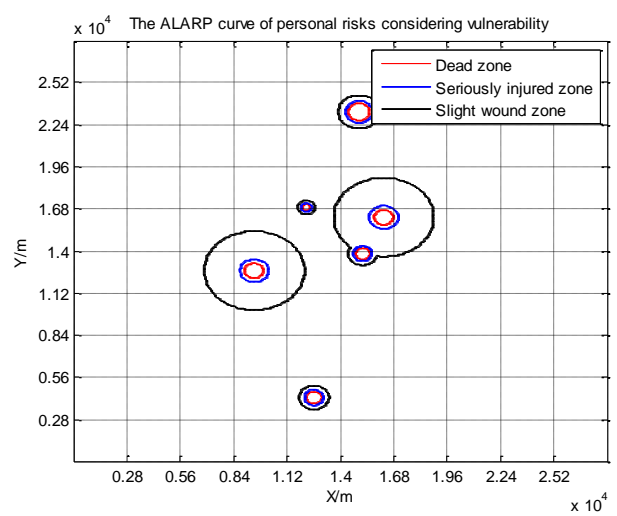

Figure 3. The ALARP curve of personal risks considering vulnerability

\subsection{Risk compensation coefficient considering equipment's vulnerability}

According to the above calculation results, we can get the social risk F-N curve of chemical industrial park as shown in table 7 and figure 4 .

Table 7. The calculation results of cumulative frequency of Risk population is greater or equal to the number $\mathrm{N}$

\begin{tabular}{|c|c|c|c|c|}
\hline $\mathrm{N}$ & $\mathrm{N}=1$ & $\mathrm{~N}=100$ & $\mathrm{~N}=150$ & $\mathrm{~N}=200$ \\
\hline probability & $3.507 \mathrm{e}-3$ & $2.9225 \mathrm{e}-3$ & $1.7535 \mathrm{e}-3$ & $1.7535 \mathrm{e}-3$ \\
\hline
\end{tabular}

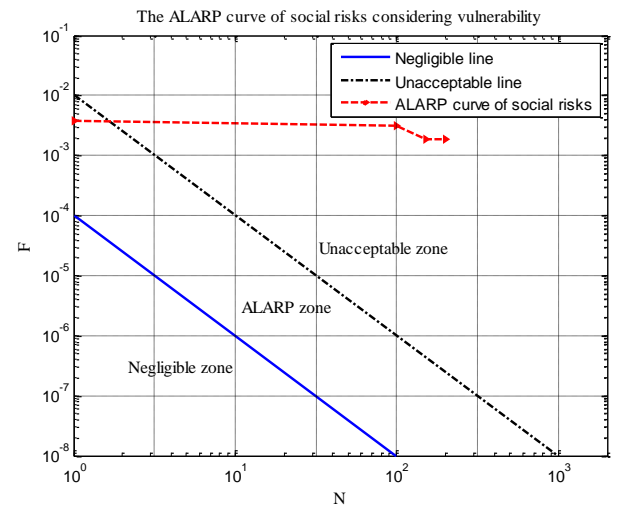

Figure 4. The social risk F-N curve of chemical industrial park s considering vulnerability

From figure 4 we can know that the social risk of chemical industrial park area is unacceptable, In order to reduce social risk, some risk management measures needed to be taken. Such as additional fire equipment in the park, set up the emergency response plan, set up fire and medical dedicated channel, reduce the population in the park.

\section{CONCLUSION}

Through the theoretical analysis and practice proving, this paper obtained the following conclusions:
1. Considering the vulnerability factors in the compensation risk, such as personal, equipment, and environment. Then established the safety of chemical industrial park planning risk model based on the vulnerability analysis indicators of personnel, equipment, and environmental and applied it to case analysis of Song Jiang chemical industrial park.

2. The result got from the method of the regional risk assessment in this paper will provide important decision support for the layout of chemical industrial park. For the chemical industrial park which has been built, the managers should consider the basic situation of the plant staff and allocate the fire and health equipment reasonable when set up and perfect the emergency rescue system, At the same time, the risk of environmental pollution should be taken seriously, once the accident happened, avoid enlarging the scope of the accident damage is important.

\section{REFERENCES}

[1] Wang Botao. Regional risk assessment based on fuzzy mathematics research. Dalian Jiaotong University, 2008.

[2] Shi Lichen, Ceng Mingrong, Duo Yingquan. Method of land-use planning based on the security consequences of application in Chemical Industry Park. Chinese of safety science and technology, 2009, 5 (6): 67-71.

[3] Chen Guohua, Zhang Jing, Zhang Hui et al. Study on regional risk assessment method. China Safety Science Journal, 2006, 16 (6): 112-117.

[4] Shi Peijun. The fifth Theory and practice of disasters research. Journal of natural disasters, 2009, 18 (5): 1-9.

[5] Zhang Bin, Zhao Qiansheng, Jiang Yujun. The regional vulnerability index system and fine quantitative model research. Disaster science. 2009, 25 (2): 36-40.

[6] Sun aijun. The accident risk assessment research on Industrial park. Nankai University, 2011.

[7] A. McIntyre, A professor of the University of Rotterdam of the United Statest. Theory of fragility and dependency. Journal of ethics research, 2003:88-90.

[8] Tang Qiuxiang. The regional quantitative safety evaluation method research on petrochemical enterprises. China uCniversity of petroleum (east China), 2010.

[9] Tan zhao-yang. The comprehensive vulnerability assessment method research on Chemical industrial park. Nankai University, 2012.

[10] Wang Hong-de, CongBo. The security risk evaluation theory and technology research on Chemical industrial park. China petrochemical press, 2012. 